\title{
ERRATUM
}

\section{Reciprocal expression of the endocytic protein HIP1R and its repressor FOXP1 predicts outcome in R-CHOP-treated diffuse large B-cell lymphoma patients}

KK Wong, DM Gascoyne, PJ Brown, EJ Soilleux, C Snell, H Chen, L Lyne, CH Lawrie, RD Gascoyne, LM Pedersen, MB Møller, K Pulford, D Murphy, TM Green and AH Banham

Leukemia (2014) 28, 470; doi:10.1038/leu.2013.276

Correction to: Leukemia (2014) 28, 362-372; doi:10.1038/ leu.2013.224; published online 13 August 2013

Since the publication of this article, the authors have identified an error contained in Figure 6 (panel c).

FOXP $1^{\text {hi }} / H I P 1 R^{\text {lo }}$ has been incorrectly listed as FOXP $1^{\text {hi }} / H I P 1 R^{\text {hi }}$.

The correct figure appears below.
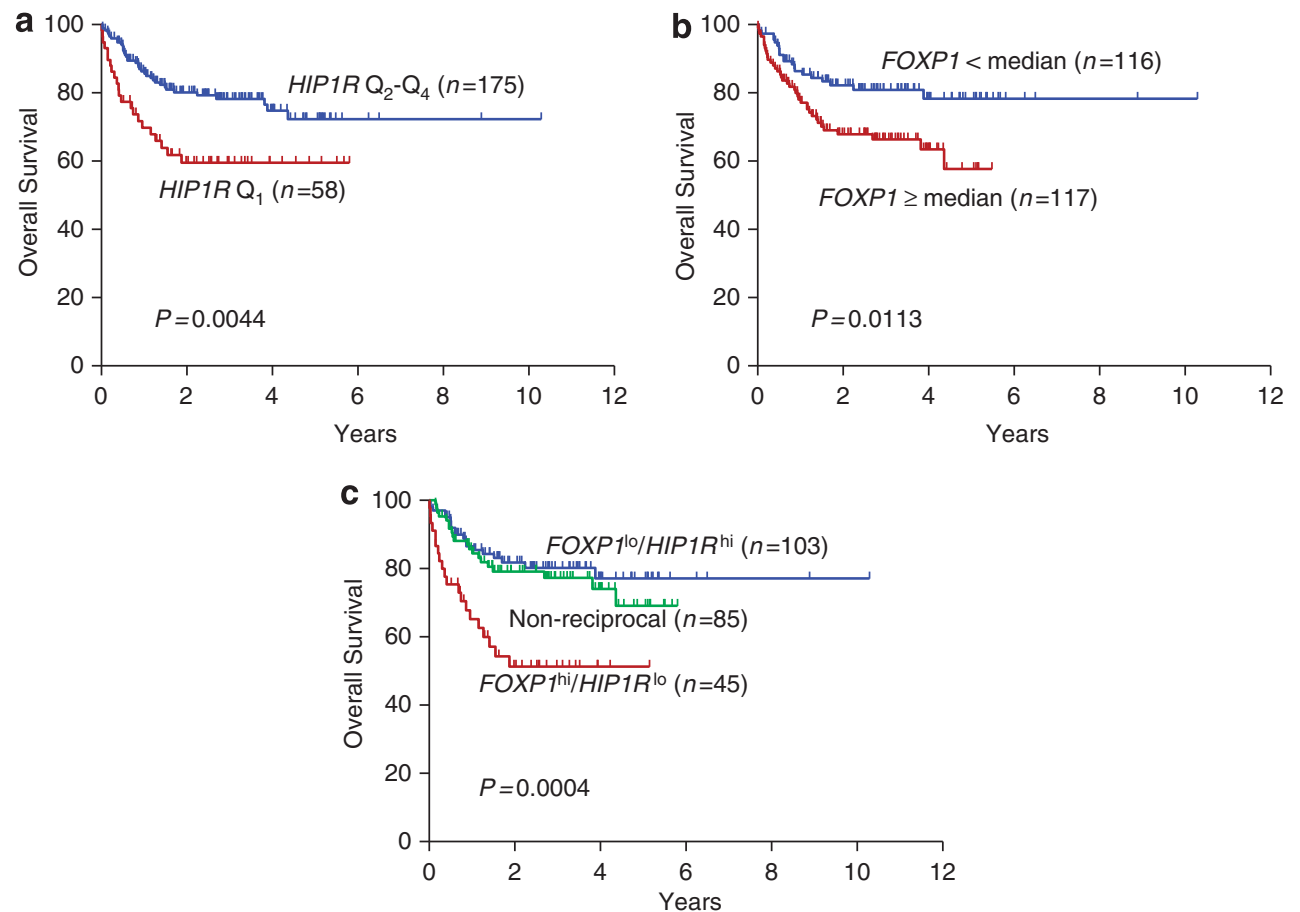

Figure 6. OS of DLBCL cases $(n=233)$ according to HIP1R, FOXP1 or combined HIP1R/FOXP1 transcript levels. Data were reanalyzed from the Lenz et $a l^{6}{ }^{6}$ data set (Gene Expression Omnibus accession no. GSE10846). Kaplan-Meier curves in (a) and (b) were grouped on the basis of the lower quartile $\mathrm{Q}_{1}$ of HIP1R or higher-than-median FOXP1 transcript values, and both cohorts showed significantly worse outcome, $P=0.0044$ and $P=0.0113$, respectively. (c) The FOXP $1^{\mathrm{hi}} / H I P 1 R^{\mathrm{lo}}$ subgroup (FOXP1 $\geqslant$ median $/ H I P 1 R \leqslant \mathrm{Q}_{1}$ ) showed a significantly inferior outcome $(P=0.0004)$.
The error has now been rectified, and the correct article appears in this issue. The html and online pdf versions have also been rectified, and now carry the correct paper.

The Publisher would like to apologize for any inconvenience this may have caused. 